\title{
IMPLEMENTATION AND EVALUATION OF COMMONLY USED RISK ANALYSIS METHODS APPLIED TO A REGIONAL POWER DISTRIBUTION SYSTEM
}

\author{
Carl Johan WALLNERSTRÖM \\ KTH - Sweden \\ cjw@kth.se
}

\author{
Patrik HILBER \\ KTH - Sweden \\ hilber@kth.se
}

\author{
Julio GADEA TRAVI \\ Gotlands Energi/Vattenfall - Sweden \\ Julio.Gadea@vattenfall.com
}

\begin{abstract}
This paper describes risk management at the power distribution system of Gotland, the largest island in the Baltic Sea. Concerns regarding that existing risk management not suit all specific conditions initiated this study. The paper shortly describes some existing risk analysis methods that could be relevant to use and summarize and evaluate performed risk analyses. The results indicated two problems with current risk management: one related to analysis methods of regional power lines $(70 / 30 \mathrm{kV})$ and the other on analysis methods used on substations. Existing methods was hence adjusted and these modified methods where then evaluated with satisfactory results.
\end{abstract}

The aim of the work is to find good risk analysis methods for a specific power system. The project is an university and industry collaboration. By describing a real case and combine industry and academic knowledge, existing methods can be evaluated and, if needed, developed. The results can hopefully be useful, both by companies that will perform risk analysis and by method developers.

\section{INTRODUCTION}

Gotland is the largest island in Sweden and in the Baltic Sea (2 $994 \mathrm{~km}^{2}$ ). The power system of Gotland is connected to the mainland by HVDC and significant amount of wind power is installed at the island. It is operated by Gotland Energy AB (owned by Vattenfall AB).

A law introduced in Sweden 2006 [1] dictates that every distribution system operator (DSO) has to annually report results from risk and vulnerability analyses regarding the reliability. An action plan of reliability improvements needed has to be included. As a result of this, development and research activities have been initiated [2], which has e.g. resulted in guidelines and proposals regarding analysis methods. Furthermore, outages 0.05-12 hours are input to quality regulation and outages $>12$ hours gives mandatory customer compensations and there exist a functional requirement that outages $>24$ not are allowed by law. Risk management largely hence focus on outages $>12$ hours [3].

In 2011, DSOs for the first time reported risk and vulnerability analyses to The Energy Markets Inspectorate (EI). This is in accordance with the EI provisions and guidelines on risk and vulnerability analysis. These reports shall be made annually. It says in the EI provisions that the reporting should be based on established risk analysis methods, such as methods described in IEC 60300-3-9 [5], Risk Analysis Method local network [6] or on risk analysis guidelines develop by Swedish government agencies.

To give DSOs an overview of the work on risk and vulnerability analyzes, Swedenergy (a non-profit Swedish industry organization) produced guidelines on risk and vulnerability analysis [4]. According to experience from the first year of reporting, IEC 60300-3-9 was the most common source [5], then the of guidelines Swedenergy. The most common analysis approach used is overall risk charting and some have used risk matrices in their work.

The aim of this paper is to find a good risk analysis method for a specific power distribution system, resulting in a recommendation of: (a) using existing risk analysis methods (b) adjust and/or complement existing methods or (c) develop new methods.

\section{RISK ANALYSIS METHODS}

\section{General risk charting approaches}

A simple, but commonly used definition of a risk value is by calculating a probability category value $P$ times a consequence category value $C$. The risk value can then be used as input to decide if and how the risk should be treated; often combined with a cost analysis.

\section{Preliminary Hazard Analysis}

The method [7] is used to identify risk sources without regard to technical system details and can be used as a first rough risk analysis. The method provides a qualitative list of hazards without numerical estimates or priorities. People with experience in similar conditions grade probabilities and consequences for a three or five-point scale and then compile these estimates and hence provide an evidencebased risk assessment.

\section{HAZOP-Hazard and Operability Study}

A method [8] which includes operating conditions; each part is analyzed on the basis that finding all probable deviations from the normal state and the reasons for them. The analysis usually starts with a group of experts from different fields doing a form of controlled "brainstorming". They look for possible deviations from planned operating conditions with the help of system description, checklists and a special system of defined key words.

"What if" analysis

The purpose of this method is to identify risk sources by 
evaluating the impact of unplanned events in the studied system. The method [9] involves an analysis of possible deviations from the planned function and operation of the system by asking questions such as: "What if ...?" The questions are formulated based on previous experience and the application is based on drawings, flow and instrumentation diagrams.

\section{Risk matrix}

A common approach to assessing a risk or comparing and prioritizing risks is the use of risk matrices. The probability and the consequence are first estimated and divided into settled categories [10]. The categorization could be made by either qualitative or quantitative methods. This gives two axes with a resulting two-dimensional matrix with estimated risk values or proposed action measures. A risk matrix is exemplified in Figure 1.

\section{Proposed method by Elforsk}

A project funded by Elforsk (Swedish Electrical Utilities' R \& D Company) resulted 2007 in the development of a risk analysis method adjusted to be easy to apply on power distribution, medium voltage level [6]. The aim of the method is to reduce the risk of severe customer outages (>12 hours). The method is using a risk matrix approach, but with three dimensions instead of two to also capture redundancy (more information in section "FORMER RISK ANALYSIS PERFORMED BY GOTLAND ENERGY", section "Risk assessment of 70/30 kV lines"). The estimated reduction of the risk value associated with a project could be compared with its estimated investment cost which gives a quotient to use when prioritizing investment proposals.

\section{Reliability analysis}

Detailed reliability analysis [11] is compared to overall risk charting approaches relatively time consuming and demands many historical fault events and is therefore not applicable in risk analysis contexts with low probabilities and major consequences. Consequently reliability analysis is a proper risk analysis approach to measure the consequence of outages during normal conditions, while other risk analysis approaches, such as using a risk matrix, ought to be taken to assess consequences of more severe events.

\section{FORMER RISK ANALYSIS PERFORMED BY GOTLAND ENERGY}

The power supply is dependent on a HVDC link. Vattenfall $\mathrm{AB}$ is responsible and handles this by starting gas turbines within 10-20 minutes and this is hence not a part of the risk analysis performed within Gotland Energy.

\section{Criteria set by Gotland Energy}

Criteria set by Gotland Energy for the usage of risk analysis is based on the established analysis methods described in [5], [6] and guidelines published by relevant Swedish government authorities. According the DSOs own investigation, limited overall assessments of the facilities have been made in the risk analysis, which includes all technical components and work processes.

\section{Risk assessment of 70/30 kV lines}

The method presented in [6] has been used for risk assessment of $70 / 30 \mathrm{kV}$ lines. The method is an overall risk analysis method based on the identification of harmful events. The method is based on following assumptions associated to its three parameters:

1. Exposure (probability parameter 1-20) - classified based on how likely it is that the feeder is affected. The probability of outages $>12$ hours depends only on feeder category and the amount of forest. Overhead lines trough weather safe corridors, by definition $>40$ meters wide, counts as non-forest, while narrower are counted as complete forest.

2. Load (consequence parameter 1-20) - classified based on how serious the consequences could be. The consequence of an outage $>12$ hours depends only on number of customers and mean load.

3. Endurance (reliability parameter 0.05-1) classified by the alternative supply routes to replace the line in case of outage. Conditions that can affect the reliability parameter are only the availability of alternative supply.

The risk value $(0.05-400)$ is derived by multiplying the three parameters with each other.

\section{Risk assessment of $10 \mathrm{kV}$ systems}

Same method used as 70/30 kV lines. No identified problems with current method at this voltage level.

\section{Risk assessment of substations}

A risk matrix method for presentation of identified events was adapted in accordance with the recommendations of EI. The method selected for the risk analysis of substations is a Preliminary Hazard Analysis, which is supplemented by assessment of probability and consequence. Reliability risks due to base events have been assessed by multiplying probability values with consequence values. The estimated risk levels for components/subsystems are noted on a worksheet in the condition monitoring of substations. The resulting risk values (1-16) are divided into three categories:

- Risk value 1-4 (green): The risk is at an acceptable level and further steps are not needed.

- Risk value 6-8 (orange): Risk reducing actions should be considered.

- $\quad$ Risk value 9-16 (red): risk reducing actions must be implemented in a near future.

\section{Risk ranking}

$70 / 30 \mathrm{kV}$ lines and $10 \mathrm{kV}$ system

Lines with the highest risk value are prioritized, i.e. those that stand out are selected for risk mitigation. 


\section{Substations}

All substations that have received a risk value in the red region of the matrix must be addressed. Substations are ranked according to their importance; the ranking of the stations that must be addressed is dependent on the load and number of customers who may be affected.

Mandatory action plan

Gotland Energy developed an action plan including 19 actions based on all risk analyses performed.

\section{EVALUATION OF PREVIOUS METHOD}

There are two parts of the performed risk analysis that are identified by Gotland Energy as relevant to address for discussion: the first is the analysis of the $70 / 30 \mathrm{kV}$ lines and the other is the analysis of substations.

\section{Evaluation of method used on $70 / 30 \mathrm{kV}$ lines}

The evaluation of previously performed analysis has indicated the importance of having well-adjusted and thoughtful probability and consequence scale categories. The score table of load (consequence 1-20): the cell with the maximum value has $>1001$ customer and a large average consumption: >50 $000 \mathrm{kWh} /$ year. It is unreasonable that so many large users exist on a local power system and hence the higher values of the scale will be unused. Furthermore, the score table is not suitable to use due to regional power systems, where there are few customers, but high individual consumption.

\section{Evaluation of method used to analyze substations}

This method is primarily aimed as a complete condition monitoring of equipments and devices of substations. The method goes through a large number of identified risks, leading to the reporting of a large number of risk points. This can be seen as a drawback of the method, because it requires a lot of preparation and systematic monitoring of the equipment in detail. The method seems proper, but it may be beneficial to reduce the number of analyzed details in each part. The method put a lot of attention to small details, but maybe it would be better to add a little more awareness towards major equipment and thus pay more attention to the component as a whole part and focus more on events with high probability of power outages. Another improvement may be to report only the orange and red risk scores to make the report more readable for decision makers.

\section{PROPOSAL OF FUTURE RISK ANALYSIS}

\section{Modified method adjusted to $70 / 30 \mathrm{kV}$ lines \\ Method}

A method is proposed that takes the systems' special structure into account. This modified risk method valuates risks of power feeders using a risk matrix. Examples of general aspects that a good risk method of regional power systems should take into account are: Non-insulated overhead lines; XLPE cables from the 70s, with high risk of ground faults; old leaking oil cables, where troubleshooting and repairs is time-consuming; cables in tunnels, which gives vulnerability of fire and hence "false" redundancy; weather secured overhead lines; redundancy; line capacity.

For the risk identification process, different scenarios that can cause severe outages are considered, e.g. by identifying whether they are critical or not in terms of an N-1 criterion and identify possibility of alternative supply. Lines that have a significant probability to cause such outages are studied further. Sections that supply small loads ( $<2 \mathrm{MW})$ are less prioritized, except if there is a risk of long outages corresponding to the Swedish laws of customer compensation and functional requirement. Lines identified as prioritized are further analyzed by using a risk matrix.

The risk matrix is used for each segment that has been identified as critical in the first step of the process. The matrix has two measurements: probability and consequence. The probability has five categories based on the estimated time between failures. The consequence has four categories based on the size of installed power and time, which give a risk value (1-20). The risk matrix is illustrated in Figure 1.

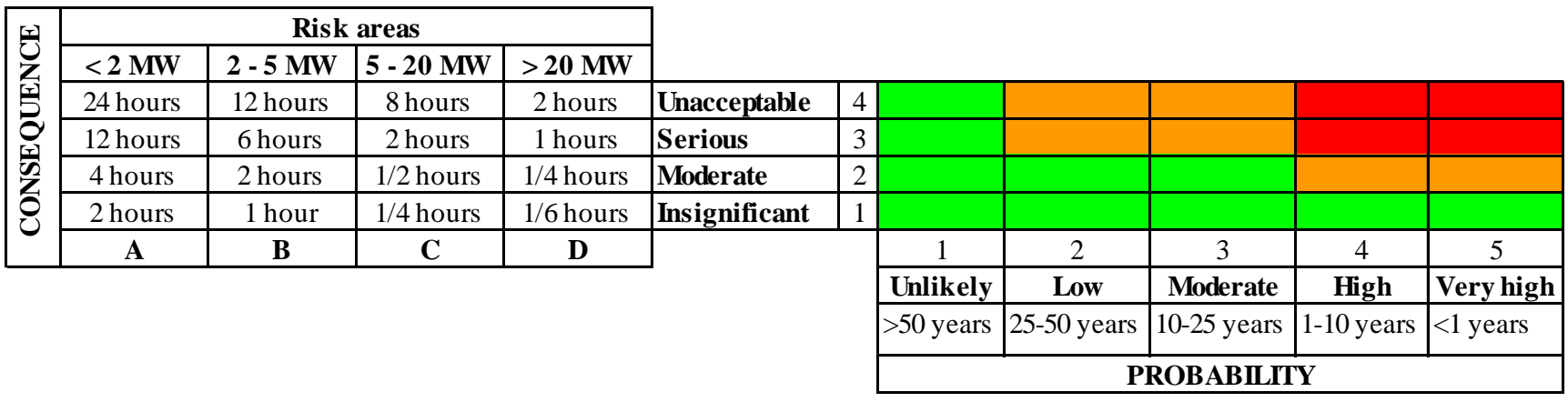

Figure 1 - Proposed risk judgment matrix according to regional power distribution $(70 / 30 \mathrm{kV}$ lines) 


\section{Implementation of proposed risk matrix}

The risk matrix has been tested on $70 / 30 \mathrm{kV}$ lines with large transmission power and on those that transmit wind power to the mainland. Example; a line that transmits 45 MW, is $29 \mathrm{~km}$ long, with an area of $329 \mathrm{~mm}^{2}$, its weather secured and got wood poles. The line has been disconnected once in the last 5 years and hence it was estimated to have 4 on the probability scale. It is possible to restore the electricity supply within $1 / 4$ hours via another line and therefore the consequence value 2 is obtained. Hence, the risk is within the orange field, see Figure 1.

\section{Evaluation}

Proposed risk analysis method for $70 / 30 \mathrm{kV}$ lines are more suited to this type of system than the previously used with high load and relatively few customers.

\section{Modified analysis method adjusted to substations} Method

The method is based on the method used by Gotland Energy according to risk analysis of substations. This is an overall risk charting approach, Preliminary Hazard Analysis, which is supplemented by assessment of probability and consequence using a risk matrix (not the same but quite similar as for power lines illustrated in Figure 1). Risk of power outages due to particular base events is assessed by multiplying a probability and a consequence category. The changes that have been made in the attempt to improve the previous method refers primarily to a reduction in the number of details analyzed and secondly the way to process the resulting risk score; however, functional requirement and the matrix are the same as in the previously conducted analysis.

In performed analysis a lot of details in a substation where analyzed separately. A station consists of a number of bays; there are transformer bays and feeder bays etc. If the transformer bay is taken as example, then all primary devices of the bay are checked: power transformer, circuit breaker, disconnector etc. However all these separate analysis can be reduced into two categories: a) component failure and b) the age of the component.

Only orange and red risk scores are reported: risks within the orange category are used as input data to a "maintenance matrix", while red are inserted in the mandatory action plan and are planned to be reduced in a near future.

\section{Implementation of proposed risk analysis method}

To test the proposed method, a substation which received high risk value in previously performed risk analysis was chosen. In this case, the substation includes: two line bays, two transformer bays, one circuit breaker for $70 \mathrm{kV}$ and one circuit breaker for $10 \mathrm{kV}$.

\section{Evaluation}

The risk analysis method that Gotland energy used originally on substations is very thorough, but it requires a lot of work to identify the risks of the devices in each bay. The new proposed method was however found to be accurate enough to identify all relevant risks, which can hence save a lot of work.

\section{CONCLUSION}

The aim of this project was to identify or develop risk analysis methods that correspond to the reality of a power distribution system with some special conditions. Existing analysis methods were evaluated, which indicated two problems with current risk management: one related to the risk analysis of $70 / 30 \mathrm{kV}$ power lines and the other on the risk analysis used on substations. Hence, existing methods were adjusted and these modified methods were then evaluated with satisfactory results. The results can hopefully be useful both by DSOs that will perform risk analysis and by them who develop new methods.

\section{REFERENCES}

[1] The Swedish Electric Power System Law, Chapter 4, ("Ellagen"), (In Swedish) (1997:857), Sweden, including updates until 2012.

[2] C. J. Wallnerström, 2011, "On Incentives affecting Risk and Asset Management of Power Distribution," Doctoral Thesis, KTH

[3] C. J. Wallnerström, L. Bertling, L. A. Tuan, 2010, "Risk and reliability assessment for electrical distribution systems and impacts of regulations with examples from Sweden", Int. Journal of Systems Assurance Eng. and Management, Vol. 1,pp 87-95.

[4] Svensk Energi, "Risk och sårbarhetsanalyser för elnät" (in Swedish), updated Dec 72010 (webpage read Feb 8 2013): http://www.svenskenergi.se/sv/Fakta-pawebben/Risk--och-sarbarhetsanalyser-for-elnat/

[5] International standard IEC 60300-3-9, "Risk analysis of technological systems"

[6] Kylefors M., Fredholm L., Sandström C., 2007, "Riskanalysmetod för lokalnät - Kartläggning och reduktion av risker i elnät”, Elforsk rapport 07:58

[7] Nuo Zhao, Tingdi Zhao, Jin Tian, 2009, "Reliability Centered Preliminary Hazard Analysis", RAMS 2009

[8] Redmill, F., 2002, "Risk analysis-a subjective process", Engineering Management Journal, vol 12, issue 2, pp. $91-96$

[9] Propst, J.E., 2001, "Improvements in modeling and evaluation of electrical power system reliability", IEEE Transactions on Industry Applications, vol. 37, Issue 5, pp. 1413-1422

[10] Nordgård DE, Samdal K., 2009, "Establishing riskbased maintenance strategies for electricity distribution companies", ESREL 2009, Prague

[11] C. J. Wallnerström and P. Hilber, 2012, "Vulnerability Analysis of Power Distribution Systems for Cost-effective Resource Allocation", IEEE Trans. on Power Systems, vol. 27, pp. 224-232 